Abstract-Understanding patterns of foraging and competition in nursery habitats can elucidate patterns of productivity in multispecies fisheries. Yellowfin sole (Limanda aspera) and northern rock sole (Lepidopsetta polyxystra) co-occur throughout the Bering Sea where they support major fisheries. We examined the diets and foraging ecology of juvenile yellowfin sole and northern rock sole (35-100 $\mathrm{mm}$ in standard length) captured along the north side of the Alaska Peninsula and in the Port Moller-Herendeen Bay system, the largest marine embayment in the southeastern Bering Sea. As observed in other parts of their ranges, the diets of both species included polychaetes and amphipods. The primary difference in the diets of these species was that the prey of yellowfin sole were almost exclusively endobenthic and epibenthic invertebrates ( $>82.7 \%$ by weight combined) and the northern rock sole consumed substantial amounts of hyperbenthic mysids and pelagic euphausiids ( $42 \%$ combined). Overall dietary overlap was low (Schoener index $[\mathrm{SI}]=0.39$ ), in part due to differences in microhabitat use. At sampling stations where both species co-occurred, dietary overlap was notably higher (SI=0.55). Patterns of functional foraging habits and juvenile niche separation that facilitate coexistence of these species throughout their range were expressed with a novel application of principal components analysis of the abiotic (habitat characteristics) and biotic (consumer traits) factors associated with commonly occurring prey types.

Manuscript submitted 11 February 2021. Manuscript accepted 9 November 2021. Fish. Bull. 120:1-12 (2021).

Online publication date: 22 December 2021. doi: 10.7755/FB.120.1.1

The views and opinions expressed or implied in this article are those of the author (or authors) and do not necessarily reflect the position of the National Marine Fisheries Service, NOAA.

\title{
Functional foraging habits and dietary overlap of yellowfin sole (Limanda aspera) and northern rock sole (Lepidopsetta polyxystra) in a coastal nursery of the Bering Sea
}

\author{
Nissa C. Ferm ${ }^{1}$ \\ Janet Duffy-Anderson ${ }^{2}$ \\ Thomas P. Hurst (contact author) ${ }^{3}$ \\ Email address for contact author: thomas.hurst@noaa.gov \\ ${ }^{1}$ Lynker Technologies LLC \\ for Resource Assessment and Conservation \\ Engineering Division \\ Alaska Fisheries Science Center \\ National Marine Fisheries Service, NOAA \\ 7600 Sand Point Way NE, Building 4 \\ Seattle, Washington 98115 \\ ${ }^{3}$ Fisheries Behavioral Ecology Program \\ Resource Assessment and Conservation \\ Engineering Division \\ Alaska Fisheries Science Center \\ National Marine Fisheries Service, NOAA \\ 2030 South Marine Science Drive \\ Newport, Oregon 97165 \\ ${ }^{2}$ Resource Assessment and Conservation \\ Engineering Division \\ Alaska Fisheries Science Center \\ National Marine Fisheries Service, NOAA \\ 7600 Sand Point Way NE, Building 4 \\ Seattle, Washington 98115
}

Understanding how species respond to variation in their environment and how they interact with their prey, predators, and competitors is critical to predicting the consequences of climate change on marine ecosystems and fisheries. Many ecosystems include pairs or groups of ecologically and morphologically similar species that co-occur in space and time. Niche separation or partitioning is generally assumed to be a critical component of community ecology allowing such species to coexist. Conversely, niche overlap is generally assumed to support ecosystem stability through efficient utilization of available resources and buffering of predator-prey linkages (Neutel et al., 2002). In the marine environment, niche partitioning and overlap are most commonly described by using physical habitat associations and diet composition (Ross, 1986).
There is a diverse assemblage of 24 flatfish species in the Gulf of Alaska (GOA) and Bering Sea (Mecklenburg et al., 2002), of which 13 species are commercially harvested (Fissel et al., 2021). In the southeastern Bering Sea (SEBS), harvest is focused on yellowfin sole (Limanda aspera) and northern rock sole (Lepidopsetta polyxystra), with several other species harvested at lower rates (Fissel et al., 2021). The yellowfin sole supports the largest fishery (by landings) of any flatfish species, worldwide. Although abundances of both species recovered from overharvesting in the 1960s and 1970s, spawning biomass of yellowfin sole has been in general decline since a peak was reached in the mid-1990s (Wilderbuer et al., 2018). Throughout their ranges, these species have overlapping distributions on the continental shelf, indicating the potential for competition. 
Nursery habitats of flatfish species are a finite space in a 2-dimensional environment where density-dependent and density-independent factors can contribute to survival and recruitment variation (Nash and Geffen, 2012). Like juveniles of many other flatfishes, juvenile yellowfin sole and northern rock sole reside in coastal waters and commonly co-occur throughout their range. The value of coastal waters as nursery habitats is frequently enhanced through warm temperatures favorable to growth, high productivity of prey resources (Wouters and Cabral, 2009), and reduced abundances of large predators (Paterson and Whitfield, 2000). Of course, the use of these nursery habitats by multiple species may increase the potential for competition.

Previous work on the feeding habits of shallow-water flatfishes in both the GOA and SEBS has revealed diets commonly dominated by polychaetes, amphipods, and copepods, with bivalves, mysids, and cumaceans being important to some species (Holladay and Norcross, 1995; Lang et al., 1995; Hurst et al., 2007; Yeung and Yang, 2017). The amount of dietary overlap among species and age classes varies considerably. In the SEBS, diets of yellowfin sole and northern rock sole have been examined in deeper areas (depths $>30 \mathrm{~m}$ ) of the shelf but not in nearshore areas along the Alaska Peninsula.

In this study, we examined the foraging habits of juvenile yellowfin sole and northern rock sole in nearshore waters of the SEBS along the Alaska Peninsula and within the Port Moller-Herendeen Bay (PM-HB) system, the largest coastal embayment of the SEBS. We focused on functional aspects of foraging and associations between diet and habitat selection that influence competition between these important species. The data from this work fill a gap and provide a baseline for future examination of the effects of climate on foraging patterns of these important flatfishes in the SEBS.

\section{Materials and methods}

\section{Field collections}

The SEBS is bordered on the east by the Alaska mainland and on the south by the Alaska Peninsula (Fig. 1). The region is characterized as a broad, gradually sloping shelf of mixed mud and sand sediments (Hurst, 2016). The PM-HB system is the largest inlet on the north side of the Alaska Peninsula. The system is a shallow (depths mostly $<10 \mathrm{~m}$ ), tidally dominated marine inlet, although the head of Herendeen Bay is fjord-like with depths up to $100 \mathrm{~m}$.

Sampling for juvenile flatfish in Port Moller (in both the inner and outer regions, IPM and OPM regions), Herendeen Bay (HB region), and the adjacent coastal waters of the Bering Sea (BC region) was carried out in August 2012 aboard the 13-m chartered FV Bountiful. A total of 75 tows were completed by using a beam trawl with a width of $3 \mathrm{~m}$, height of $0.78 \mathrm{~m}, 7-\mathrm{mm}$ mesh body, and 4-mm-mesh codend (Abookire and Rose, 2005). Depth of tows ranged from 2 to $30 \mathrm{~m}$, and tows were conducted during daylight hours. The net was towed at $1.5 \mathrm{kt}(0.77 \mathrm{~m} / \mathrm{s})$ for $5 \mathrm{~min}$ at each sampling station against the prevailing current. The length of each tow was measured by using a global positioning system. Juvenile flatfish $\leq 125 \mathrm{~mm}$ in standard length (SL) were frozen for laboratory processing. In the field, larger fish were identified to species, and their lengths were measured. The epibenthic macroinvertebrate fauna at each station was described by estimating the catch of crangonid shrimp and weighing all other benthic invertebrates in major functional groups (seastars, hermit crabs, other crabs, anemones, sand dollars, urchins, sponges, gastropods, and bivalve shells). Additional details on sampling, including catch rate at each station, can be found in Hurst (2016).

Bottom water temperature and salinity were measured with a YSI Model $85^{1}$ instrument (YSI Inc., Yellow Springs, $\mathrm{OH})$ at the midpoint of the tow. Surface sediments were collected at this location with a Ponar grab and frozen for laboratory analysis. For analysis, approximately $15 \mathrm{~g}$ of sediment was washed through a $62-\mu \mathrm{m}$ sieve, dried, and sorted with a mechanical shaker. Grain size distribution was reported as the fractions of silt-clay $(<6.25 \mu \mathrm{m})$, fine sand $(62.5-250 \mu \mathrm{m})$, medium sand (250-500 $\mu \mathrm{m})$, coarse sand $(0.5-2 \mathrm{~mm})$, and gravel $(>2 \mathrm{~mm})$. A separate sample was dried and burned at $550^{\circ} \mathrm{C}$ for determination of organic content of surface sediments.

\section{Laboratory examination}

Fish from the field were thawed and blotted dry, and species identifications were confirmed. Standard length (to the nearest millimeter) and weight (to the nearest $0.01 \mathrm{~g}$ ) were measured. From fish $<100 \mathrm{~mm}$ SL, stomachs were excised from the esophagus to the pyloric caeca and preserved in $10 \%$ buffered formalin for a minimum of 2 weeks prior to identification of stomach contents. The stomach was opened, and the bolus was extracted, blotted dry, and weighed (to the nearest $0.0001 \mathrm{~g}$ ). The bolus was examined under a compound microscope, and prey taxa were identified to the lowest possible taxon, with the majority $(67 \%)$ identified to family level. Items from the stomach were grouped into categories of identifiable taxa, enumerated, blotted dry, and weighed. Stomach fullness of each fish was calculated as a percentage of body mass (excluding the mass of prey items).

All identified prey items were associated with their AphiaID, which can be found in the World Register of Marine Species (WoRMS, available from website, accessed July 2015). The AphiaID is a searchable, unique, and stable identifier that provides taxonomic quality control (Vandepitte et al., 2015). Prey items were grouped into 4 functional habitat categories based on life history characteristics and habitat occupancy during daylight hours. The categories were endobenthic, epibenthic, hyperbenthic, and pelagic. The habitat categorization of prey taxa is used as an indication of the foraging mode, activity level,

\footnotetext{
${ }^{1}$ Mention of trade names or commercial companies is for identification purposes only and does not imply endorsement by the National Marine Fisheries Service, NOAA.
} 


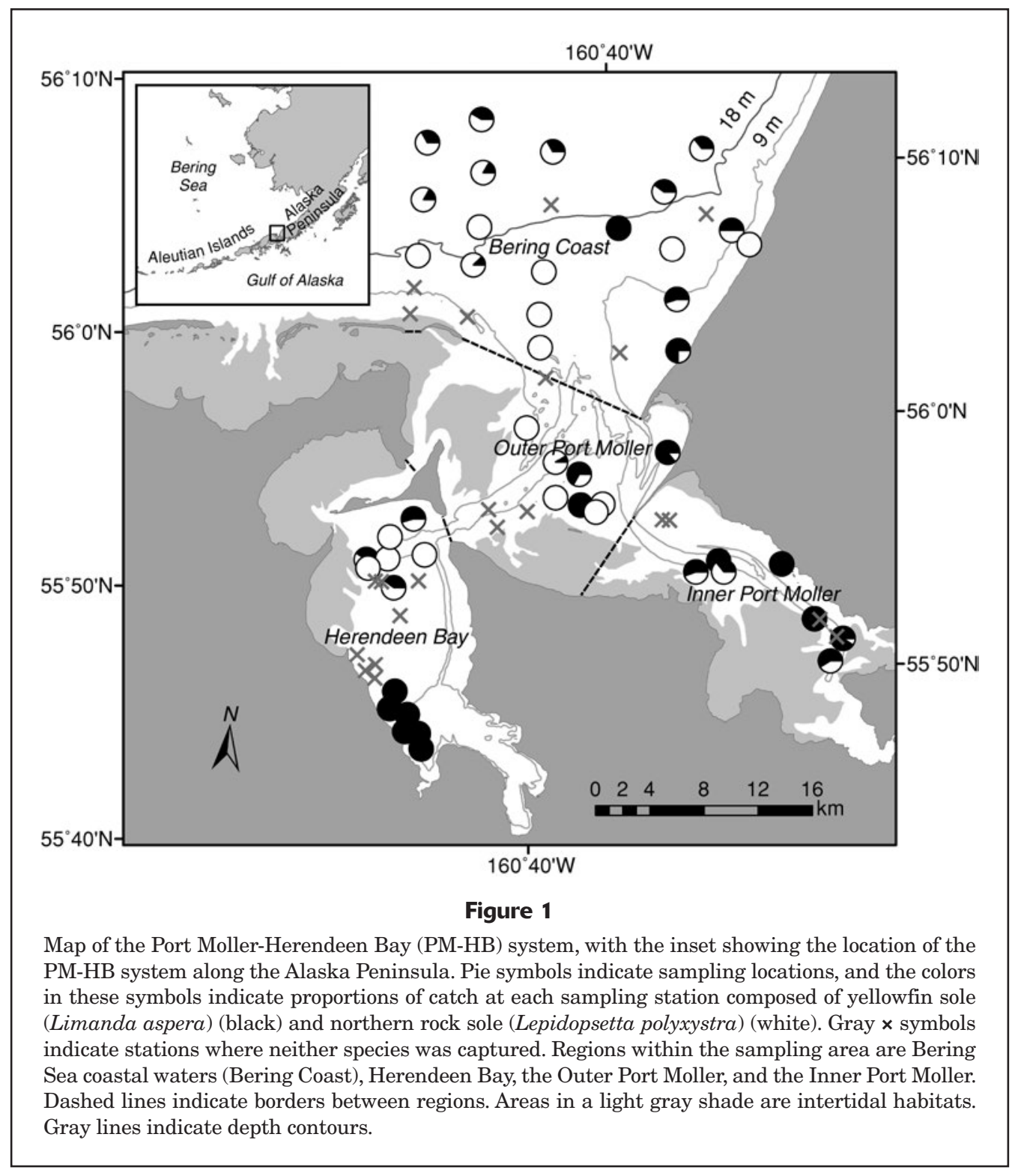

and off-bottom activity of juvenile flatfish. The endobenthic category is for organisms, such as polychaetes and bivalves, that live within the sediment. Epibenthic organisms, such as barnacles and most harpacticoids, are directly associated with the sediment surface. Hyperbenthic organisms are those that spend part or all of their time associated with the sediment but are more mobile than epibenthic organisms (Mees and Jones, 1997). Pelagic organisms inhabit the surface or water column and do not come in regular contact with the bottom.

\section{Prey taxa richness and sampling coverage}

Total species richness of the prey in diets of yellowfin sole and northern rock sole in the sampling area was estimated from extrapolation of the relationship of species richness and sample size by using the function iNEXT in the package iNEXT (vers. 2.0.20; Chao et al., 2014; Hsieh et al., 2016, 2020) in statistical software R (vers. 4.0.5; R Core Team, 2021), with 95\% confidence intervals calculated with 1000 bootstrap iterations. Non-prey (e.g., sand) and unidentifiable items were removed from all analyses. Practical limitations to prey identification resulted in prey types reflecting different levels of taxonomic aggregation. Sampling coverage provided an estimate of diet completeness, where the probability of encountering a new prey taxa in the next independent observation is 1 minus the sampling coverage from the last observed sample (Hsieh et al., 2016).

\section{Diet descriptions}

To correct diet compositions for uneven sampling coverage (stations with high catch rates represented by 
proportionally fewer diet samples), prey mass was weighted on the basis of the catch rates at each station by using this equation:

$$
W_{\mathrm{i}}^{\prime}=\frac{W_{\mathrm{i}} \times C P U E_{\mathrm{s}, \mathrm{a}, \mathrm{q}}}{n_{\mathrm{s}, \mathrm{a}, \mathrm{q}}},
$$

where $W_{\mathrm{i}}=$ the mass of prey taxon $i$;

$C P U E_{\mathrm{s}, \mathrm{a}, \mathrm{q}}=$ the catch per unit of effort for age $a$ of species $s$ at sampling station $q$ (number of individuals per $250 \mathrm{~m}^{2}$ ); and

$n_{\mathrm{s}, \mathrm{a}, \mathrm{q}}=$ the number of stomachs analyzed for age $a$ of species $s$ at station $q$.

Fish age groups were based on the length-frequency modes provided in Hurst (2016).

The prey-specific index of relative importance (PSIRI) (Brown et al., 2012) was calculated for each identified prey type to distinguish prey species and prey habitat categories that dominated the diets of northern rock sole and yellowfin sole. The PSIRI accounts for biases inherent in the standard index of relative importance of frequently occurring prey (Brown et al., 2012). The PSIRI is additive; therefore, it clarifies representation of the various levels of taxonomic identification inherent in diet studies:

$$
P S I R I=\frac{\frac{n_{\mathrm{i}}}{n}\left(\frac{\sum_{\mathrm{j}=1}^{\mathrm{n}} \% N_{\mathrm{ij}}}{n_{\mathrm{i}}}+\frac{\sum_{\mathrm{j}=1}^{\mathrm{n}} \% W_{\mathrm{ij}}}{n_{\mathrm{i}}}\right)}{2},
$$

where $\% N_{\mathrm{ij}}=$ the weighted number of prey category $i$ in stomach $j$;

$\% W_{\mathrm{ij}}=$ the weighted cumulative mass of prey category $i$ in stomach $j$;

$n=$ the total number of stomachs with identifiable prey; and

$n_{\mathrm{i}}=$ the total number of stomachs containing prey $i$.

Dietary overlap coefficients were calculated between flatfish species by using samples from all sampling stations and from only those stations where the species co-occurred. Dietary overlap was based on the Schoener Index (SI), which was calculated as follows:

$$
S I=1-\frac{1}{2}\left(\sum_{\mathrm{i}}\left|p_{\mathrm{ij}}-p_{\mathrm{ik}}\right|\right),
$$

where $p_{\mathrm{ij}}=$ the proportion by weight of prey $i$ by group $j$; and

$p_{\mathrm{ik}}=$ the proportion by weight of prey $i$ by group $k$.

The general patterns of dietary overlap are based on analyses across the full size range (35-99 $\mathrm{mm}$ SL) (Fig. 2). We also examined the potential effect of size variation on dietary overlap by using analyses that examined overlap in 2 size classes (small: $<66 \mathrm{~mm}$ SL; large: $\geq 66 \mathrm{~mm}$ SL) and by restricting data used in analysis to overlapping sizes observed in the study area (44-90 mm SL).
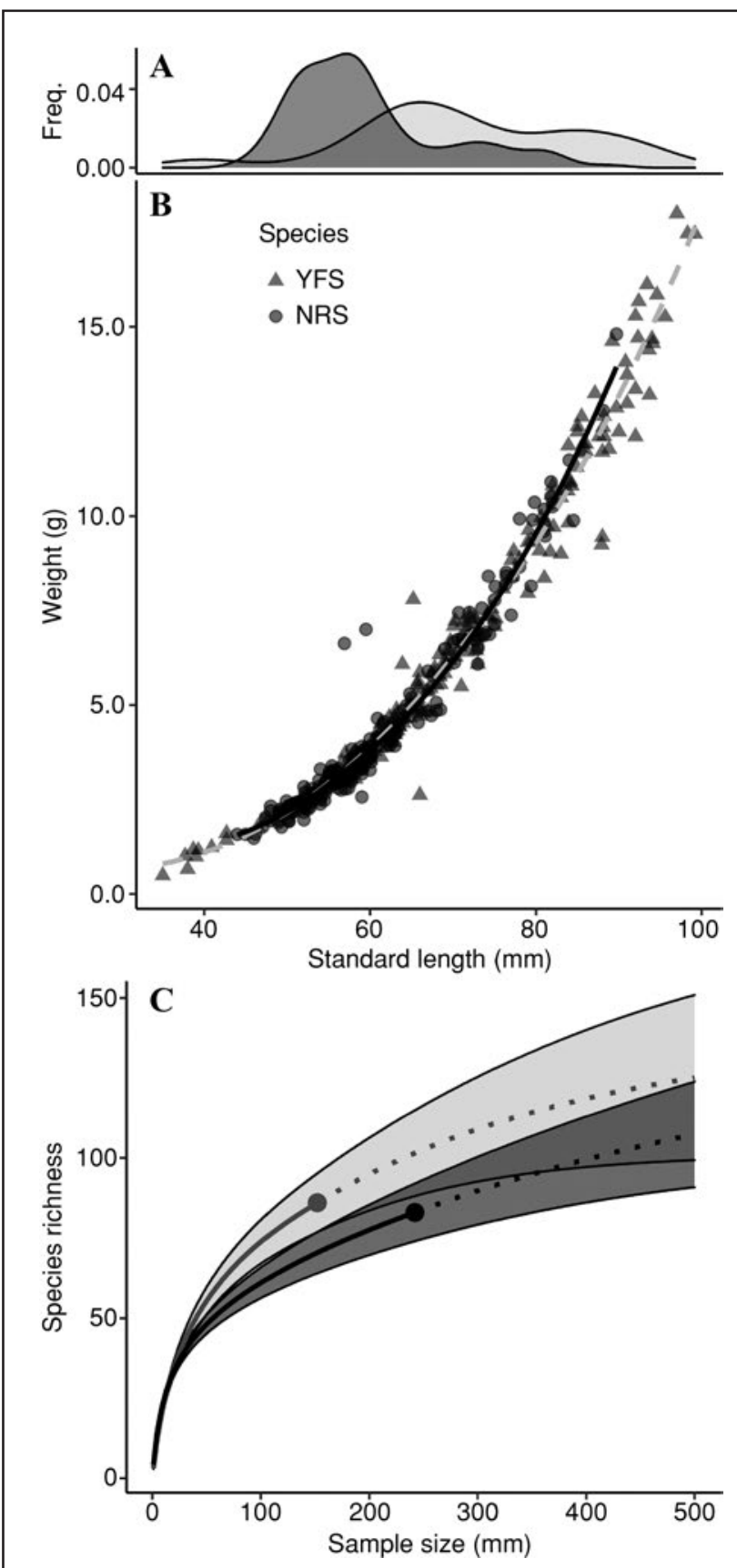

Figure 2

(A) Length-frequency distributions and (B) lengthweight relationships of yellowfin sole (Limanda aspera) (YFS) (light gray area and dashed gray line) and northern rock sole (Lepidopsetta polyxystra) (NRS) (dark gray area and solid black line) that were collected in a coastal nursery in the Bering Sea in August 2012 and that had their stomach contents analyzed. (C) Estimated species richness for prey in diets of each species based on the relationship of species richness to sample size. In panel C, for YFS (gray) and NRS (black), the circles indicate the total number of samples, the solid lines indicate interpolated estimates, and the dotted lines indicate extrapolated estimates; the light and dark gray bands indicate the 95\% confidence intervals. 


\section{Foraging patterns}

We discerned the functional foraging patterns of yellowfin sole and northern rock sole with a principal components analysis (PCA) of the environmental and biophysical features of the predation conditions for each prey taxa. This approach differs from the nonmetric multidimensional scaling analysis frequently applied in diet studies. Whereas the nonmetric multidimensional scaling approach is an ordination of samples based on the degree of co-occurrence of prey types in the diets of individual predators (or pooled by sampling location), our approach focuses on ordination of the characteristics that describe the predation event. For example, in this approach, prey taxa would be clustered in the ordination space if they were consumed at similar depths, at similar times of day, by similarly sized predators, even if they rarely co-occurred in the diets of individual predators.

For this analysis, prey taxa were grouped into broad taxonomic and habitat categories (e.g., epibenthic copepods) and retained in the analysis if they occurred $\geq 3$ times in the diets of either predator species. The matrix for each prey taxa was created by using the mean of each variable from all observations of that prey taxa. We limited the number of response variables in the prey taxa matrix to reduce occurrences of highly correlated variables. However, because of their traditional importance to habitat definitions, bottom water temperature and depth were retained despite their strong negative correlation (coefficient of determination $\left[r^{2}\right]>0.7$ ), and all sediment fractions were retained despite an $r^{2}>0.7$ for some combinations. Variables included in the analysis were consumer SL, K (Fulton's condition factor), and stomach fullness; log-transformed catch per unit of effort for the species at the station; and the corresponding environmental variables of time of day, depth, bottom water temperature, sediment proportions of silt or clay, fine sand, medium sand, coarse sand, granules, and bivalve shells. Fractions of sediment composition were logit transformed prior to analyses, and all variables were standardized prior to analyses. A single PCA of the combined prey of northern rock sole and yellowfin sole was conducted.

\section{Results}

\section{Collections}

Within the PM-HB system, juvenile yellowfin sole were more abundant than northern rock sole, but northern rock sole were more abundant in the coastal waters outside the mouth of the PM-HB system. Both species were found in all sampling areas except for the innermost stations of the $\mathrm{HB}$ region where only yellowfin sole were caught (Fig. 1). At least one of the species was captured at 47 of the 75 sampling stations, with both species being captured at 24 stations. Yellowfin sole (35-99 $\mathrm{mm}$ SL) and northern rock sole (44-90 mm SL) analyzed for this study were age 1 and age 2 (based on length-frequency distributions). A cohort of smaller age-0 northern rock sole (<35 mm SL) (Hurst, 2016) captured during sampling is not described here.

In total, diets of 443 juvenile flatfish were examined (260 northern rock sole and 183 yellowfin sole). Overall, mean stomach fullness was significantly higher in northern rock sole (1.77\% [standard error of the mean (SE) $0.14])$ than in yellowfin sole (0.22\% [SE 0.02]) (analysis of variance: $P<0.001$ ). Although this pattern was consistent across sampling regions, it was most pronounced in the $\mathrm{BC}$ region, with mean stomach fullness of northern rock sole at $2.18 \%$ (SE 0.19 ). Although samples were collected only during daylight hours (0800-2100), there was a clear pattern of feeding periodicity for northern rock sole with maximum stomach fullness observed in fish caught during 1600-1800 (Fig. 3). There was no temporal pattern in stomach fullness observed for yellowfin sole.

\section{Diet breadth}

We identified 91 distinct prey types in the diets of yellowfin sole and 85 distinct prey types in the diets of northern rock sole. Some of these prey types were common prey items that were identified to life stage within a species; whereas, other types were identifiable only to order or family. Estimates of cumulative prey richness of the diet of yellowfin sole and northern rock sole were 151.1 (SE 30.0) and 129.8 (SE 22.6), respectively, and estimates were not significantly different between predator species 
(Fig. 2). Sampling coverage for each predator species was above $90 \%$, indicating a robust description of prey diversity within the diets of yellowfin sole (93.7\% [SE 1.9]) and of northern rock sole (97.1\% [SE 0.8]) (Fig. 2).

\section{Diet composition}

Copepods, polychaetes, amphipods, and mysids were most important in the diets of both flatfish species (on the basis of PSIRI) (Table 1; for complete diet composition with all prey taxa identified from stomach contents, see Supplementary Table). Copepods were the dominant prey category for both northern rock sole and yellowfin sole, with PSIRI values of $31.4 \%$ and $32.6 \%$, respectively. Within the copepod group, an epibenthic harpacticoid, Ectinosoma sp., was the most important prey item for both species, with yellowfin sole also consuming significant amounts of hyperbenthic Eurytemora herdmandi. Polychaetes were the next most important prey group for both species with
PSIRI values of $29.3 \%$ for yellowfin sole and $19.1 \%$ for northern rock sole. Although most polychaetes could not be identified to family or genus, of those identified, the family Ampharetidae was the greatest contributor to the diets of both species. Amphipods had PSIRI values of $18.6 \%$ for yellowfin sole and $\mathbf{1 5 . 5 \%}$ for northern rock sole. Yellowfin sole consumed a diversity of amphipod species, but amphipod consumption by northern rock sole was dominated by Liljeborgia spp., Metaphoxus spp., and Photis spp. Mysids had a PSIRI of $16.0 \%$ for northern rock sole but had a PSIRI of only $4.8 \%$ for yellowfin sole.

The prey category that differed the most between the diets of the 2 flatfish species was euphausiids, which were rare in the diets of yellowfin sole (PSIRI=0.8\%) but common in the diets of northern rock sole (PSIRI=11.1\%). Thysanoessa raschii accounted for the majority of euphausiids consumed by northern rock sole.

When diet composition was expressed in percentage by weight $\left(\% \mathrm{~W}^{\prime}\right)$ of prey types, the same groups were

\section{Table 1}

Prey-specific index of relative importance (PSIRI) of the taxa of primary prey found in stomach contents of yellowfin sole (Limanda aspera) (YFS) and northern rock sole (Lepidopsetta polyxystra) (NRS) sampled in coastal areas of the southeastern Bering Sea in August 2012. Values for the 4 primary groups, Amphipoda, Copepoda, Mysidae, and Polychaeta, in the diets of sampled fish are presented, with additional details at a higher taxonomic resolution. Values are provided only for prey groups with PSIRI values $\geq 0.01$. For complete diet composition with all prey taxa identified from stomach contents, see Supplementary Table. BL=body length.

\begin{tabular}{|c|c|c|c|c|c|c|c|c|}
\hline \multicolumn{3}{|c|}{ Taxonomic groups } & \multicolumn{6}{|c|}{ Breakdown of taxa in primary groups } \\
\hline Prey group & YFS & NRS & Prey taxa & YFS & NRS & Prey taxa & YFS & NRS \\
\hline Amphipoda & 18.55 & 15.52 & AMPHIPODA & & & COPEPODA & & \\
\hline Arthropoda & 0.29 & 0.00 & Atylus collingi & 0.52 & 0.00 & Ectinosoma spp. & 24.40 & 30.89 \\
\hline Bivalvia & 0.64 & 0.07 & Caprella spp. & 0.24 & 0.00 & Ectinosomatidae & 2.67 & 0.28 \\
\hline Bryozoa & 0.01 & 0.00 & Caprellidae $<4 \mathrm{~mm} \mathrm{BL}$ & 0.04 & 0.01 & Eurytemora herdmandi & 5.33 & 0.18 \\
\hline Cirripedia & 0.58 & 0.00 & Caprellidae $>4 \mathrm{~mm} \mathrm{BL}$ & 0.03 & 0.00 & Oithona spp. & 0.10 & 0.00 \\
\hline Cnidaria & 2.60 & 0.00 & Dyopedos unispinus & 2.04 & 0.02 & Stephos spp. & 0.01 & 0.00 \\
\hline Copepoda & 32.62 & 31.35 & Eohaustorius spp. & 0.02 & 0.00 & Tigriopus spp. & 0.06 & 0.00 \\
\hline Crustacea & 0.01 & 0.00 & Gammaridea & 2.16 & 6.50 & Tisbe spp. & 0.04 & 0.00 \\
\hline Cumacea & 4.37 & 2.48 & Gammaropsis spp. & 1.56 & 0.00 & Zaus spp. & 0.01 & 0.00 \\
\hline Decapoda & 2.88 & 1.25 & Ischyroceridae & 0.13 & 0.04 & MYSIDAE & & \\
\hline Euphausiacea & 0.76 & 11.14 & Ischyrocerus spp. & 0.62 & 0.43 & Mysidae, juvenile/adult & 0.55 & 2.17 \\
\hline Pisces & 0.71 & 0.00 & Liljeborgia spp. & 0.82 & 3.53 & Mysidae, larvae & 1.07 & 5.36 \\
\hline Gastropoda & 0.27 & 0.00 & Lysianassidae & 0.53 & 0.07 & Neomysis kadiakensis & 2.62 & 6.24 \\
\hline Isopoda & 0.13 & 0.03 & Metaphoxus spp. & 0.00 & 1.94 & Pacifiacanthomysis & 0.01 & 0.00 \\
\hline Mysida & 4.79 & 15.99 & Orchomene spp. & 0.57 & 0.12 & nephrophthalma & & \\
\hline Nematoda & 0.39 & 0.23 & Orchomenella spp. & 0.37 & 0.00 & Xenacanthomysis & 0.54 & 2.22 \\
\hline Ostracoda & 0.05 & 0.00 & Pacifoculodes zernovi & 2.64 & 1.19 & pseudomacropsis & & \\
\hline Plantae & 0.76 & 0.24 & Photis macinerneyi & 1.44 & 0.63 & POLYCHAETA & & \\
\hline Polychaeta & 29.34 & 19.12 & Photis spp. & 3.10 & 0.00 & Ampharetidae & 6.25 & 2.87 \\
\hline Tunicata & 0.02 & 0.00 & Podoceropsis chionocetophilia & 0.82 & 0.90 & Maldanidae & 0.64 & 0.69 \\
\hline \multirow[t]{6}{*}{ Other } & 0.48 & 0.08 & Ramellogammarus & 0.62 & 0.00 & Nereididae & 1.46 & 0.21 \\
\hline & & & vancouverensis & & & Onuphidae & 0.65 & 2.71 \\
\hline & & & Wecomedon similis & 0.15 & 0.14 & Phyllodocidae & 1.05 & 1.30 \\
\hline & & & Unidentified Amphipoda & 0.13 & 0.00 & Spionidae & 4.90 & 1.66 \\
\hline & & & & & & Terebellidae & 0.75 & 0.01 \\
\hline & & & & & & Unidentified Polychaeta & 13.64 & 9.67 \\
\hline
\end{tabular}


identified as the primary contributors except that copepods appeared less important than when expressed in PSIRI values (Fig. 4A). Examination of diets by using the functional habitat categories of the prey revealed that yellowfin sole consumed primarily endobenthic prey $\left(\% \mathrm{~W}^{\prime}=66.0 \%\right)$, predominantly polychaetes with lesser amounts of epibenthic and hyperbenthic prey. The diet of northern rock sole also included a high proportion of endobenthic prey $\left(\% \mathrm{~W}^{\prime}=42.5 \%\right)$, but they foraged much more extensively on hyperbenthic and pelagic prey (combined $\% \mathrm{~W}^{\prime}=45.8 \%$ ), primarily mysids and euphausiids.

Polychaetes were the dominant prey in all sampling regions for both flatfishes $\left(\% \mathrm{~W}^{\prime}=33.3-65.7 \%\right)$, but there were spatial differences in contributions of secondary prey types (Fig. 4). For yellowfin sole, copepods were most important in the $\mathrm{HB}$ region $\left(\% \mathrm{~W}^{\prime}=27.4 \%\right)$, hydrozoans were common in the IPM and OPM regions (\% $\left.\mathrm{W}^{\prime} \sim 13 \%\right)$, and amphipods $\left(\% \mathrm{~W}^{\prime}=28.0 \%\right)$ and mysids $\left(\% \mathrm{~W}^{\prime}=12.9 \%\right)$ were common in samples collected in the BC region. For northern rock sole, copepods were most important in the
$\mathrm{HB}$ region $\left(\% \mathrm{~W}^{\prime}=31.9 \%\right)$, and decapods were common in the IPM region $\left(\% \mathrm{~W}^{\prime}=16.5 \%\right)$. Mysids $\left(\% \mathrm{~W}^{\prime}=20.9 \%\right)$ and euphausiids $\left(\% \mathrm{~W}^{\prime}=26.2 \%\right)$ were most commonly consumed in the BC region. Endobenthic prey dominated the diets of both species in the IPM and OPM regions, with other functional categories making significant contributions in other regions. Hyperbenthic and pelagic prey contributed the most to diets of yellowfin sole in the $\mathrm{HB}$ region and northern rock sole in the $\mathrm{BC}$ region.

Yellowfin sole and northern rock sole had low levels of dietary overlap across the study area, with an overall SI of 0.39 . This low overlap was in part a result of spatial segregation because overlap was notably higher ( $\mathrm{SI}=0.55)$ when calculated by using only fish collected at sampling stations where the species co-occurred. Within sampling regions, dietary overlap was highest in the $\mathrm{HB}$ region $(\mathrm{SI}=0.53$ ) and lowest in the OPM region ( $\mathrm{SI}=0.15$ ).

The low level of dietary overlap does not appear to have been driven by differences in body size of yellowfin sole and northern rock sole captured in the study area. The

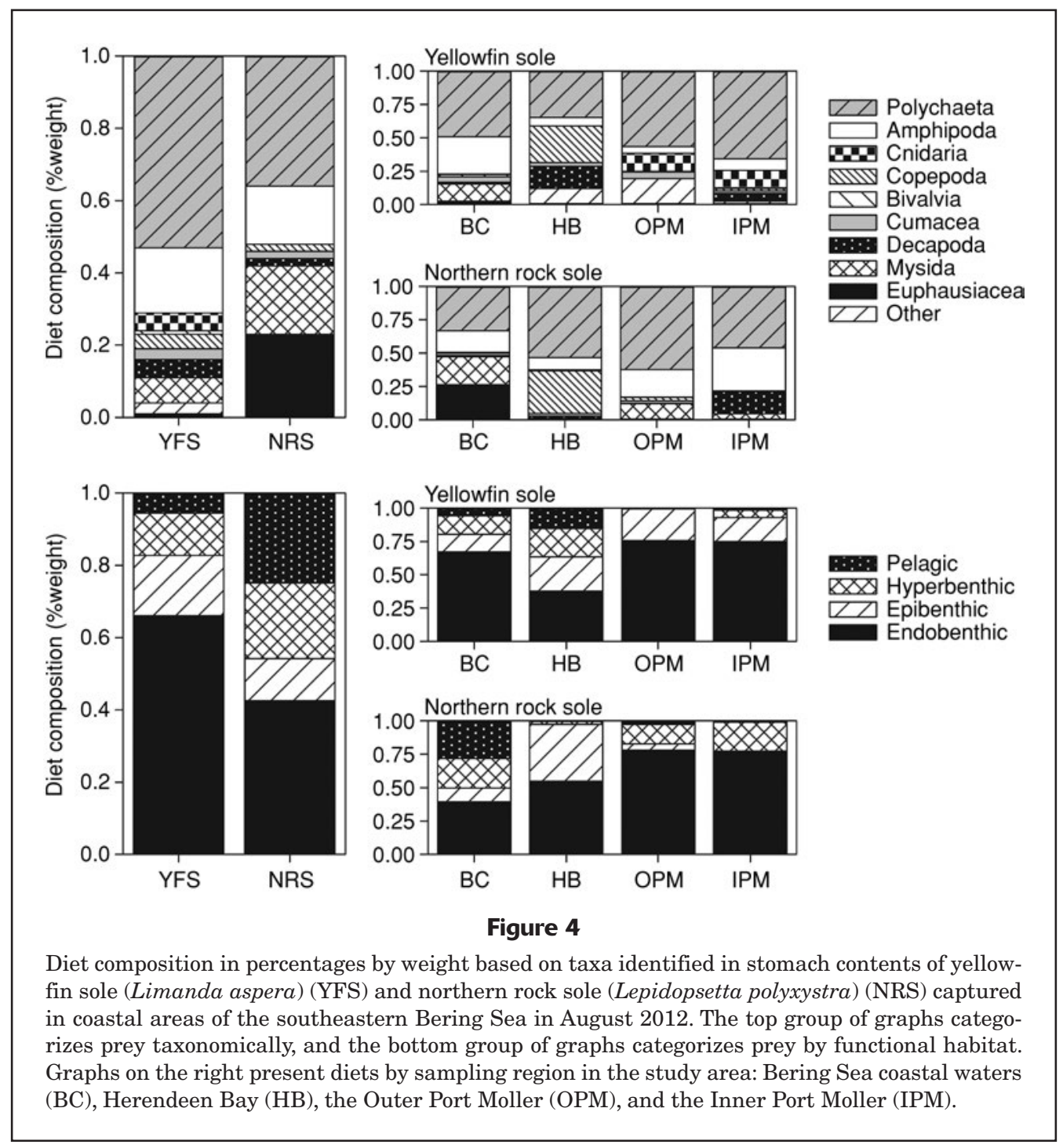


index values for dietary overlap observed within small (<66 mm SL: SI=0.42) and large ( $\geq 66 \mathrm{~mm}$ SL: SI=0.34) size classes was similar to that observed across the full size range of sampled fish (SI=0.39). Results of comparisons of overlap across size classes within species indicate more dietary overlap between size classes of northern rock sole $(\mathrm{SI}=0.70)$ than those of yellowfin sole $(\mathrm{SI}=0.40)$.

\section{Foraging characterization}

Results of PCA reveal similarities and differences in foraging patterns between yellowfin sole and northern rock sole. The first principal component (PC1) explains $41.8 \%$ of the variance and reflects differences in general foraging habitat between yellowfin sole and northern rock sole (flatfish species was not itself used as a response variable)
(Fig. 5). Yellowfin sole consumed prey in areas with higher temperature, shallower depths, and finer sediments than the areas where northern rock sole consumed prey (PC1: | coefficient of correlation $[r] \mid>0.72$ ). The PC1 is also strongly correlated with stomach fullness and time of sampling, reflecting the diel pattern of feeding and overall higher levels of stomach fullness for northern rock sole. The second principal component (PC2) explains $22.6 \%$ of the variance and is associated with the gradient between fine sand and larger sediments (medium sand, coarse sand, granules, and shells).

The PC1 scores for euphausiids and mysids consumed by both species are notably higher than those for other prey items, reflecting that their consumption occurred in deeper, cooler habitats. Euphausiids had the greatest mean depth and lowest temperature of occurrence in the diets of

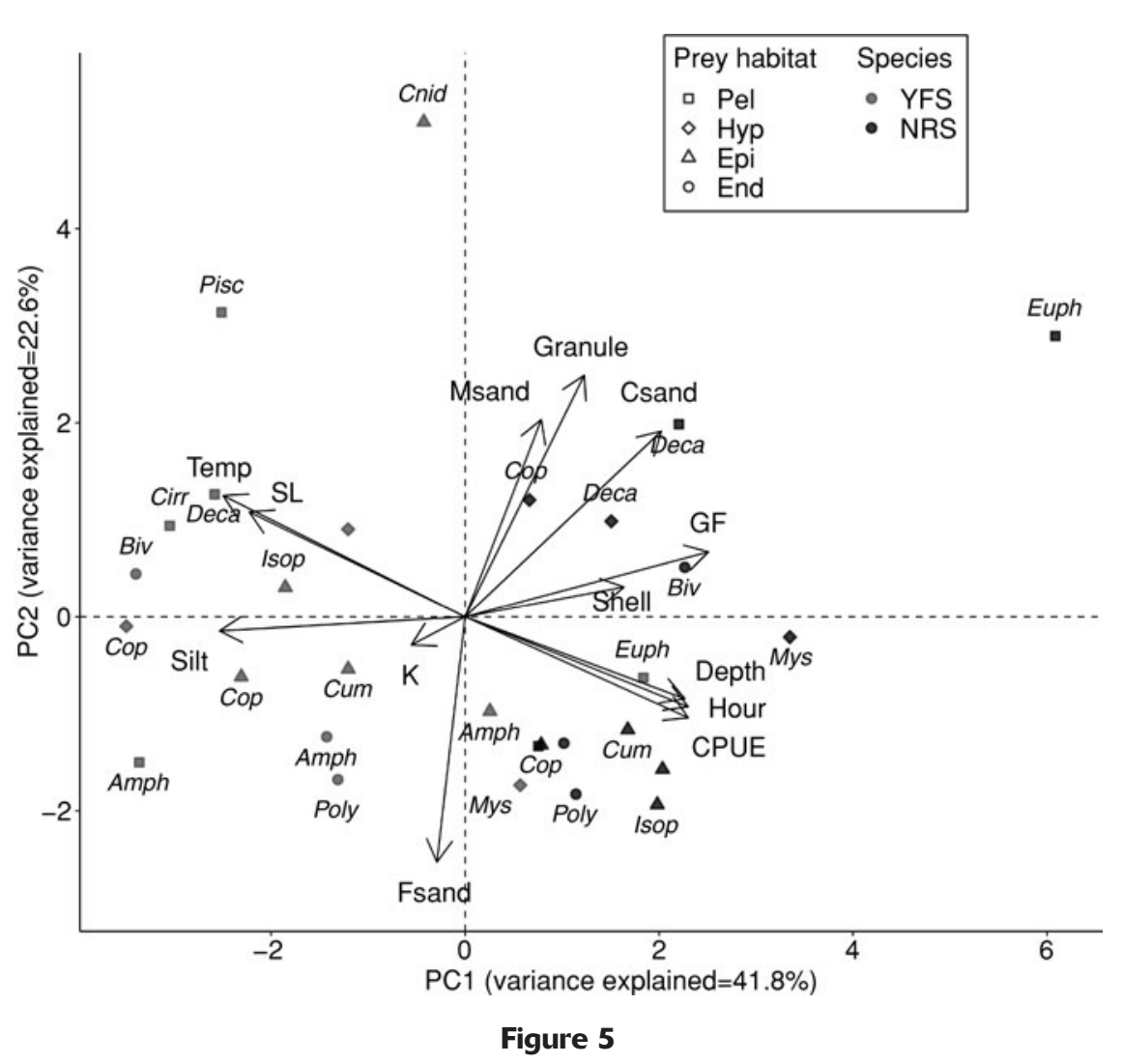

Principal component analysis of foraging patterns of yellowfin sole (Limanda aspera) (YFS) and northern rock sole (Lepidopsetta polyxystra) (NRS) captured in coastal areas of the southeastern Bering Sea in August 2012. Analysis is based on the mean value of biotic and abiotic conditions averaged across all occurrences of each prey type in stomachs of each predator species. Prey are grouped by taxonomy and habitat associations relative to the benthos: endobenthic (End), epibenthic (Epi), hyperbenthic (Hyp), and pelagic (Pel). Traits of predators are standard length (SL), stomach (gut) fullness (GF), and Fulton's condition factor (K). Traits of sampling stations are depth; temperature (Temp); sediment fractions of silt or clay (Silt), fine sand (Fsand), medium sand (Msand), coarse sand (Csand), granules, and shells; time of sampling (Hour); and catch per unit of effort (CPUE) for the predator species. Prey taxa include Polychaeta (Poly), Amphipoda (Amph), Cnidaria (Cnid), Copepoda (Cop), Bivalvia (Biv), Cumacea (Cum), Decapoda (Deca), Mysida (Mys), Euphausiacea (Euph), and Pisces (Pisc). 
both predator species. Conversely, hyperbenthic copepods (low PC1 scores) had the shallowest depth of occurrence in the diets of both predator species. Annelids (the most common prey items for both species) were consumed by both species at stations with fine sand (low PC2 score). The PCA plot (Fig. 5) also reflects some separation in foraging niche (including prey species and foraging habitat characteristics) between species: yellowfin sole consumed bivalves at relatively shallow, muddy stations, in comparison with the stations where this species consumed other prey. In contrast, northern rock sole consumed bivalves at deeper, sandier stations. Cnidaria (anemone tentacles) were not a common prey item of either species, but their high PC2 score indicates their consumption by yellowfin sole in areas with large grain sediments.

\section{Discussion}

Many flatfish species rely upon juvenile nursery habitats in shallow, coastal areas whose spatial extent is markedly smaller than that of adult distribution (Gibson, 2005). As such, flatfishes are considered particularly prone to density-dependent growth and recruitment limitations associated with interspecific competition for habitats and prey ("space concentration hypothesis;" Beverton, 1995). Furthermore, these coastal nurseries are commonly inhabited by multiple flatfish species, indicating the potential for interspecific competition and density dependence (Vinagre et al., 2005; Mariani et al., 2011). Consequently, numerous studies have examined the patterns of niche overlap and partitioning with regard to habitat associations and foraging of juvenile flatfishes (e.g., Carter et al., 1991; Vinagre et al., 2005; Tomiyama and Omori, 2008; Mariani et al., 2011). In this study, we examined the foraging habits and dietary overlap of juvenile yellowfin sole and northern rock sole in previously uncharacterized nearshore bays in the SEBS and examined functional differences in the foraging habits of these species. These observations indicate that direct competition for prey resources between juveniles of these co-occurring species is reduced by a combination of differential habitat associations and prey selection. However, this differentiation indicates that climate change in the SEBS may differentially affect the forage base and productivity of these species.

The diets of juvenile yellowfin sole and northern rock sole captured along the Alaska Peninsula of the SEBS in our study were generally similar to observations in other parts of the ranges of these species. Both species are generalist benthic invertebrate predators, with polychaetes and amphipods generally dominating their diets (Corcobado Oñnate, 1991; Holladay and Norcross, 1995; Lang et al., 1995; Hurst et al., 2007; Yeung and Yang, 2017). The incorporation of secondary diet components varied across studies. For example, bivalves were rare in the diets of both species in our sampling area, common in the diets of yellowfin sole (but not in those of northern rock sole) in broader sampling of the Bering Sea, (Lang et al., 1995), and common in diets of northern rock sole (but not in those of yellowfin sole) in coastal waters of the GOA (Holladay and Norcross, 1995; Hurst et al., 2007).

The largest difference between diets of yellowfin sole and northern rock sole was the higher occurrence of mysids and euphausiids in the diets of northern rock sole. These taxa composed $>40 \%$ (by weight) of the diets of northern rock sole but were only minor components (by weight) of the diets of yellowfin sole (mysids: 7\%; euphausiids: 1\%). Mysids and euphausiids appear to be consistently rare in the diets of juvenile yellowfin sole, with no indication of a significant contribution reported from previous studies. The incorporation of these taxa in the diets of northern rock sole appears more variable across studies, potentially varying over space and time. Mysids were rare in 2 previous studies in the SEBS (Lang et al., 1995; Yeung and Yang, 2017). Mysids were important in the diets of juvenile northern rock sole in one GOA study (Holladay and Norcross, 1995) but not in another (Hurst et al., 2007). Interestingly, in both studies in the GOA, mysids were the dominant prey of juveniles of other co-occurring flatfishes, indicating that their rarity in the diets of northern rock sole and yellowfin sole is a reflection of prey selection as opposed to availability.

The consumption of euphausiids by northern rock sole observed in our study appears to be greater than that observed in previous studies of similarly sized northern rock sole. Because euphausiids are highly aggregated, pelagic prey that undertake diel vertical migrations (Schabetsberger et al., 2000), it is possible that the conditions under which northern rock sole consume them are more limited than those for consumption of other types of prey.

\section{Dietary niche partitioning}

In waters of Alaska, yellowfin sole and northern rock sole have overlapping distributions at both the juvenile and adult stages and have been the most abundant fish species in our sampling area (Hurst, 2016). The degree of dietary overlap is an important indicator of the potential for interspecific competition between species in their juvenile nurseries. Lang et al. (1995) found high dietary overlap and potential competition between juvenile yellowfin sole and northern rock sole (fish $<200 \mathrm{~mm}$ SL in depths $<50 \mathrm{~m}$ : SI=0.70). Across our study area, the dietary overlap of these species was low ( $\mathrm{SI}=0.39$ ). The differential consumption of mysids and euphausiids contributed to the low levels of dietary overlap in our study and is likely facilitated by morphological differences between the 2 species (Barnes et al., 2021). Although flatfishes share broadly similar body morphologies, variations between species are associated with specific foraging habits (Livingston, 1987, Russo et al., 2008). Of the 2 species we studied, the northern rock sole has the more extendable jaw and a narrower field of vision, both characteristics that favor the consumption of more mobile prey (Lang et al., 1995).

The dietary niche partitioning between the species, indicated by the low overall SI values across the sampling area, was also in part due to fine-scale habitat segregation (Mariani et al., 2011). Although both 
species were widespread in the study area, northern rock sole were in deeper, colder water than yellowfin sole (Hurst, 2016). In this study, the overlap coefficient was notably higher ( $\mathrm{SI}=0.55)$ when calculated by using only fish collected at sampling locations where the species co-occurred. Interestingly, the opposite pattern was observed in coastal embayments in the GOA: dietary overlap was lower at stations where these species cooccurred than across all stations in the study area (Holladay and Norcross, 1995).

Dietary overlap indicates the potential for competitive interactions between species, but index values should be interpreted with caution. Dietary overlap may occur between species because of the shared utilization of locally abundant resources as opposed to competition for a limited resource (Carter et al., 1991). Alternatively, when species have niche separation (i.e., low dietary overlap), it can be difficult to determine if the low overlap reflects differences in habitat preferences with diets reflecting availability of prey or vice versa (i.e., consumers occupy habitats because of the availability of preferred prey). The novel approach to application of PCA to multi-species diet composition data in our study provided additional insight into foraging dynamics of the northern rock sole and yellowfin sole. This analysis included both the biotic traits of the consumer (size and Fulton's condition factor) and the abiotic aspects of their environment (depth, temperature, and sediment characteristics). The general separation between these predator species along the first axis of the PCA illustrates the difference in overall foraging habitats, with northern rock sole consuming prey in deeper waters, with more sandy sediments, and at later times of day in comparison to the diets of yellowfin sole. The separation also indicates that certain prey were predominantly consumed in specific habitats. In particular, euphausiids were consumed in deeper water than other prey by both species; whereas, hyperbenthic copepods were consumed by both species in shallow waters.

\section{Foraging patterns and predation risk}

Flatfishes possess a unique combination of morphological and behavioral adaptations associated with their demersal lifestyle. These traits indicate that avoiding detection by predators is critical to the survival of juvenile flatfish. For flatfish species, foraging activity likely directly conflicts with anti-predator behaviors that reduce conspicuousness. This trade-off is expected to be even greater when flatfish leave the sediment surface to forage in the water column because of the exposure of their unpigmented (and highly conspicuous) blind side (Hurst and Duffy, 2005). However, even within this guild, there are differences among species in behavioral characteristics.

In earlier studies that compared life history strategies of 3 co-occurring flatfishes, northern rock sole were considered the most "risk averse" in that they maintained the lowest body profile on the sediment surface and had the lowest activity rates (Lemke and Ryer, 2006).
Consistent with the finding of this risk-averse lifestyle, laboratory and field observations indicate that foraging (Corcobado Oñate, 1991; Hurst et al., 2007) and overall activity of northern rock sole were greatest during dusk periods (Hurst and Duffy, 2005). Although sampling during this study was conducted only during daylight hours, northern rock sole had a temporally restricted feeding pattern consistent with that observed in those previous studies.

Comparatively little work has been conducted on the behavioral ecology of juvenile yellowfin sole. However, several pieces of evidence indicate that their strategy may be even more risk averse than that of northern rock sole. Yellowfin sole consumed less hyperbenthic and pelagic prey whose capture presumably would entail risky offbottom swimming. In addition, Hurst (2016) found juvenile yellowfin sole at shallower depths than northern rock sole, indicating reduced encounters with large-bodied predators, as articulated in the shallow-water refuge hypothesis (Paterson and Whitfield, 2000; Linehan et al., 2001).

\section{Conclusions}

The coexistence of yellowfin sole and northern rock sole on shared nursery grounds is likely facilitated by aspects of niche separation along habitat and dietary preferences. Yellowfin sole appear to be obligate benthic foragers with narrower diets than those of northern rock sole, indicating a greater sensitivity to environmentally driven changes in availability of demersal infauna and epifauna (Poiesz et al., 2020). These differences also indicate that these species may respond differently to environmental change. Because our sampling was conducted in a comparatively cold year (in 2012) in a rapidly warming ocean region (Stabeno et al., 2017), the data from our study serve as a useful baseline for evaluating effects of climate on foodweb interactions in the SEBS. In addition to dietary differences between the 2 species, growth rates of yellowfin sole appear more sensitive to temperature variation than those of northern rock sole (Matta et al., 2010; T. Hurst, unpubl. data). Interestingly, the distribution of juvenile yellowfin sole appears to be more stable in the face of fluctuating environmental conditions than that of northern rock sole (Yeung and Cooper, 2020). This combination of narrower diet breadth, greater thermal sensitivity, and stable distribution may result in stronger environmental sensitivity in the productivity of yellowfin sole in the future.

\section{Acknowledgments}

Thanks to A. Stoner, the crew of the FV Bountiful, and staff of Peter Pan Seafoods for sampling and logistical assistance. M. Ottmar, D. Cooper, and C. Hines assisted with laboratory dissections. This project was supported by grants (to T. Hurst) for essential fish habitat studies from the Alaska Regional Office of the National Marine Fisheries Service (NMFS). C. Yeung, S. Henkel, B. Laurel, 
and 3 anonymous reviewers provided valuable comments on this manuscript.

\section{Literature cited}

Abookire, A. A., and C. S. Rose. 2005. Modifications to a plumb staff beam trawl for sampling uneven, complex habitats. Fish. Res. 71:247-254. Crossref

Barnes, C. L., A. H. Beaudreau, and R. N. Yamada.

2021. The role of size in trophic niche separation between two groundfish predators in Alaskan waters. Mar. Coast. Fish. 13:69-84. Crossref

Beverton, R. J. H.

1995. Spatial limitation of population size; the concentration hypothesis. Neth. J. Sea Res. 34:1-6. Crossref

Brown, S. C., J. J. Bizzarro, G. M. Cailliet, and D. A. Ebert.

2012. Breaking with tradition: redefining measures for diet description with a case study of the Aleutian skate Bathyraja aleutica (Gilbert 1896). Environ. Biol. Fishes 95:3-20. Crossref

Carter, C. G., D. J. Grove, and D. M. Carter.

1991. Trophic resource partitioning between two coexisting flatfish species off the north coast of Anglesey, North Wales. Neth. J. Sea Res. 27:325-335. Crossref

Chao, A., N. J. Gotelli, T. C. Hsieh, E. L. Sande, K. H. Ma, R. K. Colwell, and A. M. Ellison.

2014. Rarefaction and extrapolation with Hill numbers: a framework for sampling and estimation in species diversity studies. Ecol. Monogr. 84:45-67. Crossref

Corcobado Oñate, F.

1991. Food and daily ration of the rock sole Lepidopsetta bilineata (Pleuronectidae) in the eastern Bering Sea. Mar. Biol. 108:185-191. Crossref

Fissel, B., M. Dalton, B. Garber-Yonts, A. Hayne, S. Kasperski,

J. Lee, D. Lew, C. Seung, K. Sparks, M. Szymkowiak et al.

2021. Stock assessment and fishery evaluation report for the groundfish fisheries of the Gulf of Alaska and Bering Sea/ Aleutian Islands area: economic status of the groundfish fisheries off Alaska, 2019, 271 p. Alaska Fish. Sci. Cent., Natl. Mar. Fish. Serv., Seattle, WA, [Available from website.]

Gibson, R. N.

2005. The behavior of flatfishes. In Flatfishes: biology and exploitation (R. N. Gibson, ed.), p. 213-239. Blackwell Science, Oxford, UK.

Holladay, B. A., and B. L. Norcross.

1995. Diet diversity as a mechanism for partitioning nursery grounds of pleuronectids. In Proceedings of the international symposium on North Pacific flatfish. Alaska Sea Grant College Program Rep. AK-SG-95-04, p. 177-203. University of Alaska, Fairbanks, AK

Hsieh, T. C., K. H. Ma, and A. Chao.

2016. iNEXT: an $\mathrm{R}$ package for rarefaction and extrapolation of species diversity (Hill numbers). Methods Ecol. Evol. 7:1451-1456. Crossref

2020. iNEXT: interpolation and extrapolation for species diversity. $R$ package, vers. 2.0.20. [Available from website, accessed June 2021.]

Hurst, T. P.

2016. Shallow-water habitat use by Bering Sea flatfishes along the central Alaska Peninsula. J. Sea Res. 111:37-45. Crossref

Hurst, T. P., and T. A. Duffy.

2005. Activity patterns in northern rock sole are mediated by temperature and feeding history. J. Exp. Mar. Biol. Ecol. 325:201-213. Crossref
Hurst, T. P., C. H. Ryer, J. M. Ramsey, and S. A. Haines.

2007. Divergent foraging strategies of three co-occurring north Pacific flatfishes. Mar. Biol. 151:1087-1098. Crossref

Lang, G. M., P. A. Livingston, and B. S. Miller.

1995. Food habits of three congeneric flatfishes: yellowfin sole (Pleuronectes asper), rock sole (P. bilineatus), and Alaska plaice ( $P$. quadrituberculatus) in the eastern Bering Sea. In Proceedings of the international symposium on North Pacific flatfish. Alaska Sea Grant College Program Rep. AKSG-95-04, p. 225-245. University of Alaska, Fairbanks, AK.

Lemke, J. L., and C. H. Ryer.

2006. Risk sensitivity in three juvenile (age-0) flatfish species: does estuarine dependence promote risk-prone behavior? J. Exp. Mar. Biol. Ecol. 333:172-180. Crossref

Linehan, J. E., R. S Gregory, and D. C. Schneider.

2001. Predation risk of age-0 cod (Gadus) relative to depth and substrate in coastal waters. J. Exp. Mar. Biol. Ecol. 263:25-44. Crossref

Livingston, M. E.

1987. Morphological and sensory specializations of five New Zealand flatfish species, in relation to feeding behavior. J. Fish Biol. 31:775-795. Crossref

Mariani, S., C. Boggan, and D. Balata.

2011. Food resource use in sympatric juvenile plaice and flounder in estuarine habitats. Mar. Ecol. 32:96-101. Crossref

Matta, M. E., B. A. Black, and T. K. Wilderbuer.

2010. Climate-driven synchrony in otolith growth-increment chronologies for three Bering Sea flatfish species. Mar. Ecol. Prog. Ser. 413:137-145. Crossref

Mecklenburg, C. W., T. A. Mecklenburg, and L. K. Thorsteinson. 2002. Fishes of Alaska, 1116 p. Am. Fish. Soc., Bethesda, MD

Mees, J., and M. B. Jones. 1997. The hyperbenthos. Oceangr. Mar. Biol. 35:221-255.

Nash, R. D. M., and A. J. Geffen.

2012. Mortality through the early life-history of fish: what can we learn from European plaice (Pleuronectes platessa L.)? J. Mar. Syst. 93:58-68. Crossref

Neutel, A. M., J. A. P. Heesterbeek, and P. C. de Ruiter. 2002. Stability in real food webs: weak links in long loops. Science 296:1120-1123. Crossref

Paterson, A. W., and A. K. Whitfield.

2000. Do shallow-water habitats function as a refugia for juvenile fishes? Estuar. Coast. Shelf Sci. 51:359-364. Crossref

Poiesz, S. S. H., A. van Leeuwen, K. Soetaert, J. I. J. Witte., D. S. C., Zaat, and H. W. van der Veer.

2020. Is summer growth reduction related to feeding guild? A test for a benthic juvenile flatfish sole (Solea solea) in a temperate coastal area, the western Wadden Sea. Estuar. Coast. Shelf Sci. 235:106570. Crossref

$\mathrm{R}$ Core Team.

2021. R: a language and environment for statistical computing. R Foundation for Statistical Computing, Vienna, Austria. [Available from website, accessed March 2021.]

Ross, S. T.

1986. Resource partitioning in fish assemblages: a review of field studies. Copeia 1986:352-388. Crossref

Russo, T., D. Pulcini, À. O’Leary, S. Cataudella, and S. Mariani. 2008. Relationship between body shape and trophic niche segregation in two closely related sympatric fishes. J. Fish Biol. 73:809-828. Crossref

Schabetsberger, R., R. Brodeur, L. Ciannelli, J. M. Napp, and G. L. Swartzman.

2000. Diel vertical migration and interaction of zooplankton and juvenile walleye pollock (Theragra chalcogramma) at a frontal region near the Pribilof Islands, Bering Sea. ICES J. Mar. Sci. 57:1283-1295. Crossref 
Stabeno, P. J., J. T. Duffy-Anderson, L. B. Eisner, E. V. Farley, R. A. Heintz, and C. W. Mordy.

2017. Return of warm conditions in the southeastern Bering Sea: physics to fluorescence. PLoS ONE 12(9):e0185464. Crossref

Tomiyama, T., and M. Omori.

2008. Habitat selection of stone and starry flounders in an estuary in relation to feeding and survival. Estuar. Coast. Shelf Sci.79:475-482. Crossref

Vandepitte, L., B. Vanhoorne, W. Decock, S. Dekeyzer, A. T. Verbeeck,

L. Bovit, F. Hernandez, and J. Mees.

2015. How Aphia - the platform behind several online and taxonomically oriented databases-can serve both the taxonomic community and the field of biodiversity informatics. J. Mar. Sci. Eng. 3:1448-1473. Crossref

Vinagre, C., S. Franca, M. J. Costa, and H. N. Cabral.

2005. Niche overlap between juvenile flatfishes, Platichthys flesus and Solea solea, in a southern European estuary and adjacent coastal waters. J. Appl. Icthyol. 21:114-120. Crossref
Wilderbuer, T. K., D. G. Nichol, and J. Ianelli.

2018. Assessment of the yellowfin sole stock in the Bering Sea and Aleutian Islands, 83 p. In Stock assessment and fishery evaluation report for the groundfish resources of the Bering Sea/Aleutian Islands regions. North Pac. Fish. Manage. Counc., Anchorage, AK. [Available from website.]

Wouters, N., and H. N. Cabral.

2009. Are flatfish nursery grounds richer in benthic prey? Estuar. Coast. Shelf Sci. 83:613-620. Crossref

Yeung, C., and D. W. Cooper.

2020. Contrasting the variability in spatial distributions of two juvenile flatfishes in relation to thermal stanzas in the eastern Bering Sea. ICES J. Mar. Sci. 77:953-963. Crossref Yeung, C., and M. S. Yang.

2017. Habitat quality of the coastal southeastern Bering Sea for juvenile flatfishes from the relationships between diet, body condition and prey availability. J. Sea Res. 119:17-27. Crossref 